\title{
Clinical Aspects and Principles of Management of Tuberculosis
}

\author{
Ashfaq Hasan, Sai Haranath Praveen, Chandrakant Tarke, \\ and Fahad Abdullah
}

\begin{abstract}
Tuberculosis over the ages, has killed more people than any other infection has. Notwithstanding the advances in modern science, clinical diagnosis sometimes remains elusive, owing principally to the frequent paucibacillary occurrence of the disease and the slow doubling time of the organism; empiric treatment is often fraught with risks in the era of increasing drug resistance.

This chapter attempts to provide an overview of the disease, beginning with the pathogenesis and its protean clinical presentations. It also discusses the recent evolution of molecular methods that have lately provided an impetus to early diagnosis with a clear opportunity to unmask drug resistance before initiating "blind", potentially ineffective, and sometimes harmful treatment with standard therapy.

The chapter also provides insight into tuberculosis in special situations, and discusses briefly the treatments in uncomplicated cases as well as in special situations, and in instances of drug resistance. Preventive methods including current and upcoming vaccines are mentioned.

Finally, a short discussion of the sequelae of tuberculosis-which have the potential to be confused with active disease-is presented.
\end{abstract}

\section{Keywords}

Pulmonary $\cdot$ Infection · Tuberculosis

\footnotetext{
A. Hasan $(\bowtie) \cdot$ F. Abdullah

Department of Respiratory Medicine, Deccan College of Medical Sciences, Hyderabad, India e-mail: principal@ deccancollegeofmedicalsciences.com
}

\section{S. H. Praveen}

Department of Pulmonary and Critical Care Medicine, Apollo Hospitals, Hyderabad, India

C. Tarke

Department of Pulmonary and Sleep Medicine, Apollo Hospitals, Hyderabad, India

S. E. Hasnain et al. (eds.), Mycobacterium tuberculosis: Molecular Infection Biology, 


\section{Abbreviations}

$\begin{array}{ll}\text { ADA } & \text { Adenosine deaminase } \\ \text { ADRs } & \text { Adverse drug reactions (ADRs) } \\ \text { AFB } & \text { Acid-fast bacilli } \\ \text { AIDS } & \text { Acquired immunodeficiency syndrome } \\ \text { ARDS } & \text { Acute respiratory distress syndrome } \\ \text { ART } & \text { Antiretroviral therapy } \\ \text { ATT } & \text { Anti-tubercular therapy } \\ \text { BAL } & \text { Broncho-alveolar lavage } \\ \text { BCG } & \text { Bacillus Calmette-Guerin } \\ \text { DOTS } & \text { Directly observed treatment } \\ \text { EMB } & \text { Ethambutol } \\ \text { GABA } & \text { Gamma-aminobutyric acid } \\ \text { HIV } & \text { Human immunodeficiency virus } \\ \text { INH } & \text { Isonicotinylhydrazide } \\ \text { IRIS } & \text { Immune reconstitution syndrome } \\ \text { LAM } & \text { Lipoarabinomannan } \\ \text { LPA } & \text { Line probe assays } \\ \text { LTBI } & \text { Latent TB infection } \\ \text { MDR-TB } & \text { Multiple drug-resistant TB } \\ \text { MGIT } & \text { Mycobacteria growth indicator tube } \\ \text { MICs } & \text { Minimum inhibitory concentrations } \\ \text { NAAT } & \text { Nucleic acid amplification technology } \\ \text { PAS } & \text { Para-amino salicylic acid } \\ \text { PPD } & \text { Purified protein derivative } \\ \text { SAT } & \text { Self-administered therapy modified } \\ \text { TB } & \text { Tuberculosis } \\ \text { WHO } & \text { World Health Organization } \\ \text { XDR } & \text { Extensive drug resistant } \\ & \\ & \end{array}$

\subsection{Introduction}

TB can involve all organs except the nails, hair and teeth [Ekaterina Kulchavenya. Ther Adv Infect Dis. 2014 Apr;2(2): 61-70]. Pulmonary TB is the most common form of TB. The symptomatology of TB has to do with its pathogenesis, the specific organ system involved and the duration of the disease.

Primary TB, which occurs in the Mycobacterium-naive individual, usually presents with a frequently occult primary focus in the peripheral lung parenchyma (Stead's focus) accompanied by a pleural effusion; or by a primary focus-frequently inapparent - in the lower part of the upper lobe or the upper part of the lower lobe (Ghon's focus) accompanied by lymphadenopathy. Other manifestations of 
primary TB such as erythema nodosum or phlyctenular conjunctivitis may be present. In young children with immature cellular immunity, or in immunocompromised individuals, the process may evolve to progressive primary disease.

Symptoms and signs relate to the compressive effect of enlarged lymph nodes on adjacent structures (collapse or hyperinflation of a lobe or segment), or rupture of caseating lymph nodes into a bronchus, with bronchiectasis later supervening in such a lobe.

Post-primary disease, the typical adult form of TB, usually occurs by reactivation of a dormant focus-or less frequently, by reinfection; the better aerated lung apices are preferentially involved. The classical triad of the constitutional symptoms of TB (fever, night sweats, weight loss) - most usually of several weeks' duration-is present in a high proportion of patients (Heemskerk et al. 2015).

The extent of disease at the time of first diagnosis may be variable, from patchy consolidation to a large cavity. This not only reflects the protean pulmonary forms of the process but also has to do with host immunity, the virulence of the strain and, most of all, with the time elapsed between disease onset and diagnosis.

Cavitation is an important milestone in the timeline of the post-primary pulmonary tuberculosis. With ingress of O2-rich air into a fresh cavity (caused by the coughing out of a caseous collection), the aerobic Mycobacterium is presented with an opportunity to multiply manifold in an aerobic environment: the infectiousness of the subject (and the possibility of a positive diagnosis on sputum testing) commensurately increases (Golub et al. 2006). Cavitation also increases the propensity to haemoptysis (which may sometimes be massive) and that of cavitary colonization with a fungal ball (mycetoma) later on in healed disease. One third of all individuals affected with post-primary TB die within a few months ("galloping consumption") (Reported tuberculosis in the United States, 2013 2014). The remainder either go on to develop a chronic pattern with a more gradual progressive decline or undergo spontaneous remission of the process and restoration to health. With chronicity, fibrosis is common.

Disseminated TB, which often casts "miliary" shadows in the lungs, occurs due to haematogenous dissemination following either primary or post-primary TB. The name derives from the resemblance of the widespread granulomatous lesions to millet seeds (seen in pathological specimens as 1-2 $\mathrm{mm}$ yellow granules). Symptoms may be nonspecific and depend on the site and degree of organ involvement. Hepatosplenomegaly, lymphadenopathy and pleural effusions may be present. Fundus examination, often neglected, will frequently show choroid tubercles, which are virtually diagnostic of the condition in a likely setting.

Diagnosis often hinges on microbiology from broncho-alveolar lavage (BAL) or on biopsy of involved organs (Lewinsohn et al. 2017) though it may occasionally be made on sputum (sponaneously expectorated or induced).

Disseminated TB Disseminated TB should always raise suspicion for an accompanying immune deficiency such as HIV disease. Sometimes an occult disseminated form of TB ("cryptic miliary TB") presents as a "fever of unknown origin", usually in the elderly or immunocompromised patients. In difficult cases 
(as with the classic miliary form), bone marrow or liver biopsy with Mycobacterial cultures may be diagnostic.

Unlike the post-primary form of disease, untreated miliary TB is predictably fatal.

\section{Extra-Pulmonary Tuberculosis}

Extra-pulmonary tuberculosis has been increasingly seen since the advent of the HIV epidemic. TB can involve any organ of the body (other than nails, hair and teeth). Organ systems typically involved include pleura (pleural effusions), lymph nodes (generally cervical or mediastinal), airway (endobronchial tuberculosis), skeletal (joint or vertebral involvement, sometimes with a psoas abscess), gastrointestinal, genitourinary, meningeal and pericardial involvement. Symptoms pertain to the system involved, but diagnosis may be difficult unless a high degree of suspicion is maintained. Tissue or fluid samples from the involved organs with staining, Mycobacterial cultures or molecular probe assays are often diagnostic although radiological patterns in specific cases may be very suggestive of the process (e.g. vertebral involvement with a paraspinal abscess) (Lewinsohn et al. 2017).

\section{Diagnosis}

The diagnosis of tuberculosis, especially in the developed nations, rests on the keystone of suspicion. Physical examination is generally unrewarding. Auscultation of the lung typically underestimates the lung problem relative to that seen on imaging. With a pleural effusion, breath entry is typically decreased, with a flat note over the effusion. Cavernous bronchial breathing may be detected over a cavity, and tubular bronchial breathing over an area of consolidation or dense fibrosis.

The radiologic features in the various forms of pulmonary TB have already been discussed above under the relevant heads.

Microbiological isolation of the Mycobacterium tuberculosis on culture has been the only definitive test for TB thus far, though it could be argued that molecular probes for specific mycobacterial genes and other technologies (discussed below and also elsewhere in this book) offer viable and more attractive options for diagnosis. Presumptive diagnosis is typically achieved by microscopy (usually of sputum, but also of fluid obtained by BAL and other means) (Pai et al. 2016).

Mycobacteria, not being stainable by "conventional" stains, require a modified acid stain (the Ziehl-Neelsen method) in order to be visualized; LED microscopy though relatively expensive, by making the bacilli easy to see under low power, enables more fields to be scanned in a shorter period of time, and thus increases the sensitivity of microscopy several-fold (Bhalla et al. 2013).

Conventional culture methods are slow (4-6 weeks, less by radiometric assays), and frequently there is a compelling need to start appropriate anti-tubercular therapy as early as possible. Rapid culture techniques are now in universal use. They use liquid rather than solid media. The Mycobacteria growth indicator tube (MGIT) method takes days rather than weeks and facilitates drug sensitivity testing. 
Since relapses (see below) occur in approximately $5 \%$ of patients after 6 months of standard therapy, it is a moot point whether establishment of minimum inhibitory concentrations (MICs) in the presence of a "critical concentration" of drug is relevant in selected cases (Colangeli et al. 2018).

Automated nucleic acid amplification technology (NAAT) has the potential of amplifying even a fragment of mycobacterial DNA rapidly (in $2 \mathrm{~h}$ ) and has revolutionized TB diagnosis. In its currently available form, the GeneXpert test is intended specifically to diagnose Mycobacterium tuberculosis (and thereby differentiate it from other Mycobacteria such as environmental Mycobacteria), and also presumptively diagnose rifampicin resistance.

Though not invariable, rifampicin resistance also implies INH resistance. Together, rifampicin and INH resistance fulfil the diagnosis of multiple drugresistant TB (MDR-TB). Thus a positive GeneXpert test makes a presumptive diagnosis of MDR-TB (Steingart et al. 2009). The test is more sensitive than direct microscopy and extremely specific (Steingart et al. 2014). The test is not infallible, however, and any result that is discordant with the clinical picture should either be repeated or further information sought using another modality. False-positive NAAT results can occur due to laboratory contamination. Importantly, NAAT can detect nucleic acid from dead non-viable bacilli, and so a positive test after completion of the course of treatment has no relevance in that situation (Boyles et al. 2014) nor is it of relevance in monitoring response to treatment (Friedrich et al. 2013). It is important to realize that NAAT is not a substitute for AFB smear and culture testing; culture is essential for species identification and for drug susceptibility testing (Cheng et al. 2005). A more sensitive version of Xpert has been developed.

The line probe assays (LPA) can permit rapid identification of specific gene markers associated with rifampicin resistance alone or in combination with isoniazid, and provide clinically relevant information about the level of INH resistance (low level associated with the INH-A gene; versus high level associated with the kat-G gene) (WHO treatment guidance for drug resistant tuberculosis 2016).

Definitive diagnosis has traditionally hinged on the culture characteristics of MTB: species discrimination can be achieved on the basis of colony morphology as well as on the basis of biochemical tests performed on the culture. Conventional culture (Lowenstein-Jensen medium and its variants) is capable of detecting as few as ten bacteria per millilitre with the sensitivity and specificity of sputum culture approximating 80 and 98\%, respectively (Morgan et al. 1983). Following initial culture, species identification is done by any of the following techniques: biochemical methods (testing, nucleic acid hybridization probes, high-pressure liquid chromatography or mass spectrophotometry). Drug sensitivity testing is subsequently carried out, usually at a reference laboratory (Shinnick and Good 1995) to first-line anti-tubercular agents, but sometimes to second-line agents as well when resistance to components of first-line anti-tubercular agents has been documented. In individuals living with HIV who have CD4 counts $<100$ cells $/ \mathrm{mm}^{3}$, or those who are immunocompromised, Mycobacterial cultures of blood and urine should complement conventional testing. Point-of-care urinary detection of lipoarabinomannan, a component of the Mycobacterial cell wall (urine LAM 
test) may be useful for HIV-infected individuals, and its use may possibly confer a mortality benefit (Reported tuberculosis in the United States, 2013 2014). The future of point-of-care devices is next-generation sequencing, and, perhaps, innovations like detection of volatile organic compounds in exhaled breath (Garcia-Basteiro et al. 2018)

Serological tests (tests for antibodies against TB) have poor sensitivity and specificity; false-positive tests are ubiquitous, and serologic testing for the diagnosis of TB is discouraged by the WHO.

A pleural fluid adenosine deaminase (ADA) $>35 \mathrm{U} / \mathrm{L}$ has been reported to be $93 \%$ sensitive and $90 \%$ specific for the diagnosis of pleural TB in lymphocytic exudates (Garcia-Zamalloa and Taboada-Gomez 2012).

\subsection{TB in Special Circumstances}

\subsubsection{TB in Childhood}

TB infection can rapidly progress to disease in infants and young children (progressive primary TB). Mortality is high in early childhood because of the severe forms of TB (such as miliary TB and meningeal TB) that occur more frequently in young children. Progressive primary TB is a serious consequence of primary tuberculosis. Consolidation or bronchopneumonia is more common than cavitary disease in children. Haematogenous dissemination leading to miliary TB is also more common in infants and young children. Tubercular pleural effusion, however, is less common in children below 5 years of age.

Central nervous TB is the most serious form of childhood TB (Prevention 2014). The presentation is usually with nonspecific symptoms such as fever, headache, drowsiness and irritability, but in advanced cases, vomiting, neck rigidity, seizures, focal neurologic deficit and coma may supervene.

Since sputum samples for diagnosis are difficult to obtain in young children (children tend to swallow sputum rather than expectorate), gastric washings can rather be sent for microbiological examination. A PPD test that is greater than $10 \mathrm{~mm}$ in BCG-unvaccinated children and $>15 \mathrm{~mm}$ in BCG-vaccinated children is considered positive. (Targeted tuberculin testing and treatment of latent tuberculosis infection. This official statement of the American Thoracic Society was adopted by the ATS Board of Directors, July 1999. This is a Joint Statement of the American Thoracic Society (ATS) and the Centers for Disease Control and Prevention (CDC). This statement was endorsed by the Council of the Infectious Diseases Society of America. (IDSA), September 1999, and the sections of this statement 2000.)

The principles of treatment of tuberculosis in children are similar to that of adults. Paediatric TB patients should be monitored carefully for ethambutol-induced ocular toxicity, owing to the fact that children are less likely to report visual impairment than adults.

In a prospective study of children on multidrug-resistant tuberculosis, children had lower serum concentrations in spite of higher dosing of moxifloxacin, a 
fact that was ascribed to increased drug elimination in children. Quinolones have also been known to rarely cause arthropathy and tendon rupture. More recent studies have shown that most quinolones are quite well tolerated but very specific and narrow indications are present for quinolone use in children (Patel and Goldman 2016).

\subsubsection{TB in Pregnancy}

Tuberculosis in pregnancy has important implications for the mother and child (Loto and Awowole 2012).

The diagnosis of tuberculosis in pregnancy can be challenging, since many of the symptoms of early TB may be confounded by pregnancy; for instance, the normal weight gain in pregnancy may temporarily mask the associated weight loss. Chest radiograph is not an absolute contraindication and when necessary may be carried out with "abdominal shielding" of the fetus.

The complications of TB in pregnancy include early spontaneous abortion, intrauterine growth retardation, preterm delivery, low birth weight and increased neonatal mortality. Congenital TB is rare, but can be associated with high perinatal mortality.

First-line oral drugs, i.e. isoniazid, rifampicin, ethambutol and pyrazinamide, can all be used during pregnancy safely. Streptomycin and other aminoglycosides have been proven to be potentially teratogenic in pregnancy. They are also capable of causing eighth nerve paralysis, with deficits ranging from mild hearing loss to bilateral deafness (Loto and Awowole 2012). Concerns have been raised about the use of fluoroquinolones in pregnancy even though the weight of the evidence seems to point toward safety (Acar et al. 2019)

\subsubsection{TB in HIV}

TB is considered an AIDS-defining disease [Centers for Disease Control and Prevention. Appendix A: AIDS-Defining Conditions. MMWR. 2008;57(RR10):9]. The risk of developing TB is estimated to be between 16 and 27 times greater in people living with HIV than among those without HIV infection. HIV and TB have a salutary impact upon each other and expedite each other's progression. The risk of progressing from latent to active TB is estimated to be between 12 and 20 times greater in people living with HIV than among those without HIV infection (Global TB report 2017).

Against the backdrop of HIV infection, the rate of progression of TB from the acquisition of infection to full-blown disease may take weeks, rather than years-as is the case in HIV-negative individuals (Mayer and Dukes Hamilton 2010). It is important to realize that TB can occur at all "stages" of HIV disease. The clinical presentation of HIV patients who have relatively high CD4 counts is no different to that which occurs in individuals without HIV. Such individuals manifest with the 
classical manifestations of post-primary tuberculosis such as upper lobe infiltrates. On the other hand, lower lobe involvement, pleural effusions and intrathoracic lymphadenopathy are common in individuals with low CD4 counts (typically $<200 / \mu \mathrm{L}$ ). Indeed the chest X-ray may sometimes only show vague interstitial infiltrates or even be normal (Mayer and Dukes Hamilton 2010). Taken together, the fact that in advanced HIV disease (a) the sputum is less likely to be positive for AFB (b) the PPD is usually non-reactive (c) the X-ray abnormalities are likely to represent other opportunistic infections or even non-infective conditions associated with HIV disease and (d) histopathology of involved tissues is characterized by lack of typical granulomata; these considerations make the diagnosis extremely challenging in this setting. In addition, there is increased frequency of extra-pulmonary TB among HIV-positive individuals.

Frequently, a positive NAAT (GeneXpert) test is the justification for starting treatment. However it must be cautioned that even a negative NAAT test cannot convincingly rule out disease, and, given that delays in treatment may be fatal, the decision to initiate treatment is sometimes taken on clinical grounds.

\subsection{Treatment of TB}

The treatment of tuberculosis differs from the treatment of most other infections in certain respects. Multiple drugs are required in a regimen since spontaneous mutations can lead to resistance to the action of one or more drugs. Also, because the bacterium is relatively slow growing, it takes longer to achieve bacteriologic sterility. Multidrug therapy, the norm for TB, has been very effective, with a modest rate of relapse (Colangeli et al. 2018).

The standard four-drug regime ("short course") comprises a 2-month intensive phase with the four front-line drugs (rifampicin, isoniazid, ethambutol and pyrazinamide), followed by a continuation phase with the drugs (minus pyrazinamide and possibly ethambutol) for a further 4 months.

The four front-line drugs have been chosen based on their efficacy in rapidly reducing the number of organisms initially (during the initial phase), thus reducing infectivity; and on their sterilizing potential (the ability to eradicate viable bacteria completely and so prevent relapses); and their relative lack of side effects (see Table 20.1). These drugs are combined into regimens.

The six classes of second-line agents (fluoroquinolones, the aminoglycosides, capreomycin, ethionamide and prothionamide, para-amino salicylic acid (PAS), cycloserine and terizidone) have a rather lower efficacy and a higher propensity for side effect and drug intolerance. Several other antibiotics of uncertain efficacy have also been categorized as anti-tubercular agents and have a role in treating multidrug-resistant TB (MDR-TB) (see Table 20.2).

Two new agents, bedaquiline (a diaryl-quinolone) and delamanid (a nitroimidazole), are now approved for the treatment of MDR-TB.

The WHO recommends using a daily regimen and fixed-dose combinations (Guidelines for treatment of drug-susceptible tuberculosis and patient care 2017). 
Table 20.1 First-line agents for standard first-line anti-tubercular therapy

\begin{tabular}{|c|c|c|}
\hline Drug & $\begin{array}{l}\text { Adult } \\
\text { daily dose }\end{array}$ & Comment \\
\hline \multirow[t]{2}{*}{ Isoniazid } & \multirow[t]{2}{*}{$5 \mathrm{mg} / \mathrm{kg}$} & $\begin{array}{l}\text { Give pyridoxine } 10 \mathrm{mg} \text { daily to prevent peripheral neuropathy; if } \\
\text { established peripheral neuropathy, give pyridoxine } 50-75 \mathrm{mg} \\
\text { daily }\end{array}$ \\
\hline & & Protect tablets from light \\
\hline Rifampicin & $10 \mathrm{mg} / \mathrm{kg}$ & Preferably given $30 \mathrm{~min}$ before food \\
\hline Pyrazinamide & $25 \mathrm{mg} / \mathrm{kg}$ & $\begin{array}{l}\text { Avoid with active hepatic disease (see further discussion on drug } \\
\text { induced hepatitis, below); adjust dose for renal function }\end{array}$ \\
\hline \multirow[t]{2}{*}{ Ethambutol } & \multirow[t]{2}{*}{$15 \mathrm{mg} / \mathrm{kg}$} & Adjust dose for renal function \\
\hline & & $\begin{array}{l}\text { Ocular examination to be done before and periodically during } \\
\text { treatment }\end{array}$ \\
\hline
\end{tabular}

Administration of the drugs on a daily basis both during the intensive and during the continuation phase is preferable although daily administration during the initial phase and intermittent (thrice weekly) administration during the continuation phase is also acceptable (Guidelines for treatment of drug-susceptible tuberculosis and patient care 2017). Intermittent administration of drugs (especially in the initial phase) is not offered in the presence of HIV disease.

If at the end of the intensive phase the bacteria are sensitive to the three most important agents (isoniazid, rifampicin and pyrazinamide), ethambutol may be discontinued (Nahid et al. 2016). However, drug testing for three of the four frontline drugs for each patient at the end of the intensive phase is impractical, and limited testing (GeneXpert) is usually performed initially in those patients whose sputum remains positive. There is evidence to show that extending the continuation phase by 7 months (making up a total duration of treatment of 9 months) helps in preventing relapse in those patients who have cavitation on initial chest X-rays; and also in those who show positive cultures at the end of the initial phase of treatment (Benator et al. 2002); as well as in those whose medication given during the initial phase did not include pyrazinamide.

Anti-tubercular drugs require to be supplemented with carefully monitored steroid therapy in two circumstances: tubercular meningitis (a short course of dexamethasone or prednisolone is typically given, tapered over 6 to 8 weeks) and tuberculous pericarditis (Guidelines for treatment of drug-susceptible tuberculosis and patient care 2017).

Since many patients cannot be relied upon to regularly take their drugs, and irregular intake of drugs has the potential to result in drug resistance (see Treatment Failure and Relapse; and Drug Resistant TB, below), it is imperative to ensure adherence to the regimen. Directly observed therapy, short-course (DOTS) is the direct observation by another person, of the patient taking the medication (Chaudhuri 2017). The use of DOTS has improved adherence in subgroups of patients such as TB with HIV or if DOTS was at the site of DOTS centre or provider location. 
Table 20.2 First and second-line anti-tubercular agents and their adverse drug reactions (ADRs)

\begin{tabular}{|c|c|c|c|}
\hline Drugs & Common ADRs & Uncommon ADRs & Rare ADRs \\
\hline Isoniazid* & $\begin{array}{l}\text { Asymptomatic } \\
\text { elevation of serum } \\
\text { hepatic enzymes }\end{array}$ & $\begin{array}{l}\text { Hepatitis, cutaneous } \\
\text { hypersensitivity, } \\
\text { peripheral neuropathy }\end{array}$ & $\begin{array}{l}\text { Fever, giddiness, } \\
\text { convulsions, optic } \\
\text { neuritis, mental } \\
\text { symptoms, haemolytic } \\
\text { anaemia, aplastic } \\
\text { anaemia, lupoid reactions, } \\
\text { arthralgia, gynaecomastia }\end{array}$ \\
\hline Rifampicin* & Pruritus & $\begin{array}{l}\text { Hepatitis, cutaneous } \\
\text { hypersensitivity, } \\
\text { gastrointestinal } \\
\text { reactions, } \\
\text { thrombocytopenia, } \\
\text { febrile reaction, "flu } \\
\text { syndrome" }\end{array}$ & $\begin{array}{l}\text { Shortness of breath, } \\
\text { shock, haemolytic } \\
\text { anaemia, acute renal } \\
\text { failure, thrombotic } \\
\text { thrombocytopenic } \\
\text { purpura }\end{array}$ \\
\hline Pyrazinamide* $^{*}$ & $\begin{array}{l}\text { Anorexia, nausea, } \\
\text { flushing, } \\
\text { photosensitization }\end{array}$ & $\begin{array}{l}\text { Hepatitis, vomiting, } \\
\text { arthralgia, cutaneous } \\
\text { reactions }\end{array}$ & $\begin{array}{l}\text { Sideroblastic anaemia, } \\
\text { gout }\end{array}$ \\
\hline Ethambutol $^{*}$ & & $\begin{array}{l}\text { Retrobulbar neuritis, } \\
\text { cutaneous reactions, } \\
\text { arthralgia }\end{array}$ & Peripheral neuropathy \\
\hline Streptomycin & $\begin{array}{l}\text { Cutaneous } \\
\text { hypersensitivity, } \\
\text { giddiness, } \\
\text { numbness, tinnitus }\end{array}$ & $\begin{array}{l}\text { Vertigo, ataxia, } \\
\text { deafness }\end{array}$ & $\begin{array}{l}\text { Clinical renal failure, } \\
\text { aplastic anaemia }\end{array}$ \\
\hline Thioacetazone & $\begin{array}{l}\text { Gastrointestinal } \\
\text { reactions, cutaneous } \\
\text { hypersensitivity, } \\
\text { vertigo, } \\
\text { conjunctivitis }\end{array}$ & $\begin{array}{l}\text { Hepatitis, erythema } \\
\text { multiforme, exfoliative } \\
\text { dermatitis, haemolytic } \\
\text { anaemia }\end{array}$ & Agranulocytosis \\
\hline $\begin{array}{l}\text { Amikacin/ } \\
\text { kanamycin/ } \\
\text { capreomycin }\end{array}$ & $\begin{array}{l}\text { Hearing damage, } \\
\text { vestibular } \\
\text { disturbance, } \\
\text { deranged renal } \\
\text { function tests }\end{array}$ & Clinical renal failure & \\
\hline $\begin{array}{l}\text { Ofloxacin/ } \\
\text { ciprofloxacin }\end{array}$ & $\begin{array}{l}\text { Gastrointestinal } \\
\text { reactions, insomnia }\end{array}$ & $\begin{array}{l}\text { Anxiety, dizziness, } \\
\text { headache, paresthesia, } \\
\text { tremor }\end{array}$ & $\begin{array}{l}\text { Convulsion, cutaneous } \\
\text { hypersensitivity }\end{array}$ \\
\hline $\begin{array}{l}\text { Ethionamide/ } \\
\text { prothionamide }\end{array}$ & $\begin{array}{l}\text { Gastrointestinal } \\
\text { reactions }\end{array}$ & $\begin{array}{l}\text { Hepatitis, peripheral } \\
\text { neuropathy }\end{array}$ & $\begin{array}{l}\text { Convulsion, depression, } \\
\text { alopecia, hypothyroidism, } \\
\text { impotence, } \\
\text { gynaecomastia }\end{array}$ \\
\hline Cycloserine & $\begin{array}{l}\text { Dizziness, } \\
\text { headache, } \\
\text { depression, memory } \\
\text { loss }\end{array}$ & Psychosis, convulsion & Sideroblastic anaemia \\
\hline $\begin{array}{l}\text { Para- } \\
\text { aminosalicylic } \\
\text { acid }\end{array}$ & $\begin{array}{l}\text { Gastrointestinal } \\
\text { reactions }\end{array}$ & Hepatitis, drug fever & $\begin{array}{l}\text { Hypothyroidism, } \\
\text { haematological reactions, } \\
\text { generalized } \\
\text { hypersensitivity, } \\
\text { malabsorption }\end{array}$ \\
\hline
\end{tabular}

*First line anti-tubercular agents 
Self-administered therapy (SAT) modified with some form of monitoring incorporated into the process shows some promise. Although DOTS could be administered by a family member, the preferred person is a trained lay provider or healthcare worker (Guidelines for treatment of drug-susceptible tuberculosis and patient care 2017).

The treatment of TB in HIV disease merits special consideration. Antiretroviral therapy (ART) should be started irrespective of the clinical stage of HIV disease and CD4 count. Anti-tubercular therapy (ATT) should precede the commencement of ART. ART should then be commenced as soon as it is evident that ATT is being tolerated (typically between 2 weeks and 2 months).

The immune reconstitution inflammatory syndrome (IRIS) is sometimes seen with the returning immune competence that follows ART; an increased immune response to tubercle bacilli or antigens occurs. IRIS usually occurs between 1 and 3 months of the commencement of ART and is associated with a decrease in viral load and an increase in CD4+ T cell count. There is a worsening in the clinical picture weeks or months into treatment, with an increase in the size of lymph nodes, development of pleural effusions and features of noncommunicating hydrocephalus in a patient with TB meningitis.

Although most patients with IRIS have mild to moderate symptoms, IRIS, especially when related to TB meningitis, can be life-threatening. An "unmasking IRIS” may occur in patients with unsuspected TB (Raviglione 2017).

Treatment of IRIS includes addition of steroids (which probably work by decreasing the levels of pro-inflammatory cytokines) and the continuation of ATT and ART.

With both ATT and ART on board, drug-drug interactions especially involving rifampicin (by induction of the cytochrome P450 system) may occur. Rifamycins induce the metabolism of non-nucleoside reverse transcriptase inhibitors and protease inhibitors. Rifampicin is a more potent inducer of the cytochrome P450 system than rifapentine, which in turn is more potent than rifabutin. Despite potential drug interactions, rifamycins should nevertheless be included in TB regimens, with dosage adjustment if necessary. Rifabutin is the preferred rifamycin in HIV-positive individuals.

\subsection{Alternative Treatment Approaches}

Host-directed therapy to modulate the immune response to TB is an active area of research (Kaufmann et al. 2014). The use of an anti-diabetic drug-metformin, for example-is being investigated. Also, studies of autologous mesenchymal stromal cell infusions is being investigated in MDR and XDR-TB (Skrahin et al. 2014). An approach using high-altitude sanatoria was also explored (Murray 2014) in a throwback to the pre-anti-tubercular chemotherapy era. Study using atypical Mycobacterial injection in tuberculous did not show any major outcome differences from placebo although steroids did decrease the subsequent development of constrictive pericarditis (Mayosi et al. 2014). 
Given the role that vitamin D plays at the level of the antigen-presenting cell, the role of vitamin D deficiency as a possible player in TB predisposition has recently come into focus; indeed a recent meta-analysis has revealed that vitamin D supplementation in fact did not affect time to sputum culture conversion overall, though it did accelerate sputum culture conversion in patients with multidrug-resistant pulmonary tuberculosis (Jolliffe et al. 2019).

\subsection{Critical Care of Patients with TB}

Patients with TB may be admitted to an ICU for a variety of reasons, including respiratory failure, multiorgan failure, decreased consciousness associated with tubercular meningitis, pneumothorax, cardiogenic shock (due to massive pericardial effusion) and liver or kidney failure due to a drug reaction induced by ATT. Confluent tuberculous bronchopneumonia and TB ARDS are less common causes of respiratory failure (Hagan and Nathani 2013).

Tuberculosis treatment is especially challenging in critically ill patients due to potential for poor gastric absorption and the high rates of organ dysfunction and drug toxicity in this subset of patients. Deciding the optimal regimen and dosing becomes challenging in the presence of concomitant hepatic and renal failure. In a recent study done on TB patients requiring ICU admission, mortality was 72.5\% (Tatar et al. 2018).

\subsection{Treatment Failure and Relapse}

Treatment failure is suspected when the sputum remains positive for AFB at the end of the first 3 months of treatment. It occurs due to factors that may involve incorrect regimens or dosing or indeed due to malabsorption or poor-quality drugs (Lambregts-van Weezenbeek and Veen 1995). Patients are regarded as treatment failures when a microbiologic indicator like sputum smear/culture for TB remains positive after 3-4 months of starting treatment or comes back positive after a period of remaining negative (fall and rise phenomenon) (Prasad et al. 2018). Patients may respond for a short time after starting treatment or do not respond to treatment from the inception. In any case the implication of treatment failure is drug-resistant TB (see below), and strenuous efforts must be made to look for microbiological resistance to first-and, in the proper context, to second-line agents-by the available tools. Relapse, on the other hand, is the recurrence of TB after completion of treatment that has been successful, with documented culture negativity. Relapse may be due either to a reinfection or reactivation of the dormant bacillus. Drugresistant TB is to be considered in these settings. The implications of relapse are not as grave, the isolates generally being drug sensitive.

In either case, the exact regimen chosen should be based upon the drug sensitivity pattern. Specific recommendations upon the construction of such a regimen are 
available at WHO treatment guidelines for drug-resistant tuberculosis 2016 update (http://www.who.int).

\subsection{Drug-Resistant TB}

Drug-resistant TB is a major global problem and is a threat to the success of the End TB strategy. MDR-TB or multidrug-resistant TB (MDR-TB) is defined by resistance of $M$. tuberculosis against to at least rifampicin and isoniazid. Since these two drugs are the most effective drugs available against TB, resistance to both considerably shortens the odds of complete cure.

XDR-TB or extensively drug-resistant TB is defined as resistance to rifampicin and INH plus resistance to at least one fluoroquinolone and one second-line injectable agent (amikacin, kanamycin or capreomycin).

Some of the reasons that lead to drug resistance have been mentioned in the section above. However the most important of these are failure to comply with the treatment regimen on the part of the patient and the addition of a single drug ("monotherapy") to a failing regimen; or a situation of unrecognized primary (that which is present at the start of therapy) or secondary (that which develops during treatment) drug resistance.

INH mono-resistance of itself probably does not impact the outcome of therapy provided that ethambutol and possibly pyrazinamide are used for the entire duration of therapy. Consideration should be given in this case to extending the duration of treatment to 9 months from the standard 6 (Sadanand 2011). For reasons already discussed, rifampicin-resistant individuals should be managed as MDR-TB patients. In such patients it is not unusual to encounter resistance to additional drugs (e.g. ethambutol).

It has been shown that clinical cure is possible in patients with MDR and even XDR-TB (WHO drug resistant TB 2016). However, owing to a variety of reasons not the least of which is drug intolerance, only about half of MDR-TB and a third of XDR-TB patients ever complete therapy. The WHO estimates there are over 600,000 MDR-TB or rifampicin-resistant cases annually (Global TB report, WHO update 2017; wwww.who.int). The treatment of MDR-TB and XDR-TB is complex and requires specialized knowledge and close monitoring to ensure rational and safe therapy (Lange et al. 2018).

The choice of drugs for treatment of MDR-TB is frequently difficult. Formulation of drugs into regimens is facilitated by the organization of drugs into groups:

Group A = levofloxacin/moxifloxacin, bedaquiline, linezolid.

Group B = clofazimine, cycloserine/terizidone.

Group $\mathrm{C}=$ ethambutol, delamanid, pyrazinamide, imipenem-cilastatin, meropenem, amikacin (streptomycin), ethionamide/prothionamide, p-aminosalicylic acid.

The WHO makes specific recommendations for short and long MDR-TB regimens. In the WHO's 2018 update (WHO treatment guidelines for multidrug- 
and rifampicin-resistant tuberculosis 2018), for those MDR-TB patients "who have not been previously treated for more than one month with second-line medicines used in the shorter MDR regimen or in whom resistance to fluoroquinolones and second-line injectable agents has been excluded," the WHO permits a shorter MDR-TB regimen of 9-12 months.

For $\mathrm{MDR} / \mathrm{RR}(\mathrm{RR}=$ rifampicin resistant $) \mathrm{TB}$ patients on longer regimens, the WHO recommends that "all three Group-A agents and at least one Group-B agent (should) be included to ensure that treatment starts with at least $4 \mathrm{~TB}$ agents likely to be effective, and that at least three agents (are) included for the rest of treatment after bedaquiline is stopped. If only one or two Group A agents are used, both Group B agents are to be included. If the regimen cannot be composed with agents from Groups A and B alone, Group C agents are added to complete it. Kanamycin and capreomycin are not to be included in the treatment of MDR/RR-TB patients on longer regimens" (WHO treatment guidelines for multidrug- and rifampicin-resistant tuberculosis 2018). A detailed discussion about the treatment of MDR-TB is available at the foregoing resource.

Novel anti-tubercular agents (e.g. bedaquiline and delamanid) have been discussed elsewhere in this text.

\subsection{The Sequelae of Tuberculosis}

The remodelling of the lung that follows TB can significantly contribute to morbidity and mortality. Haemoptysis is frequently one of the remote sequelae and can on occasion be life-threatening. An unresolved cavity is frequently the cause, and bleeding from an unsupported blood vessel in the cavity wall or in a post tubercular bronchiectatic segment can be a source of troublesome bleed. Cavities colonized by fungi (aspergillomas), broncholiths eroding into the bronchial wall and rarely expansion and subsequent rupture of an unsupported blood vessel in the cavity wall (Rasmussen's aneurysm) can cause massive haemoptysis (van den Heuvel and van Rensburg 2006). A scar carcinoma sometimes develops in an area of fibrosis and may sometimes be difficult to distinguish from a dense fibrotic infiltrate (Gao et al. 2015). Post-tubercular bronchiectasis is predisposed to when caseation necrosis and inflammation with retention of secretions leads to destruction of bronchial walls with ensuing permanent dilatation. Sometimes compression of bronchial lumen by enlarged lymph node can produce bronchiectasis by a different mechanism. Postprimary TB involves the upper lobes of the lung, and so the gravitationally advantaged upper lobes do not usually undergo a process of chronic and recurrent infection unlike the lower lobes that are involved by bronchiectasis of other aetiologies.

Mycetoma (fungal ball) is a mass of fungal hyphal material that grows within a cavity. Aspergillus fumigatus is the most common aetiological agent, but other fungi such as Mucor or Fusarium can also cause a fungal ball to develop (Rippon 1988). Such a mycetoma is usually asymptomatic but can sometimes lead to haemoptysis. 
No treatment required in asymptomatic cases, but surgical treatment needs to be considered in patients with massive or recurrent haemoptysis.

\subsection{Side Effects of Treatment}

A list of adverse effects associated with anti-tubercular agents appears in Table 20.2. Side effects are possible with any of the anti-tubercular agents, and on rare occasions, they may be serious and even fatal. The risk of liver injury with antiTB therapy is always a concern. Among the four first-line agents INH, rifampicin and pyrazinamide are all capable of causing hepatotoxicity. Isoniazid is capable of causing asymptomatic mild elevation in transaminases in 15-20\% as well as fatal severe acute hepatitis in $0.05-1 \%$. Jaundice with liver injury can occur in $0.5-1 \%$. Peripheral neuropathy due to pyridoxine deficiency can occur with INH therapy in up to $6.5 \%$ of elderly individuals (Ruan et al. 2018); pyridoxine supplementation is required for all patients taking INH (John 2019). Factors increasing the chances of INH hepatotoxicity include age, female gender, alcohol use, prior hepatitis, concurrent use of cytochrome-inducing agents and slow acetylator status (Sharma et al. 2016). Acute INH toxicity can present as seizures due to decreased GABA levels. INH is metabolized to several metabolites including the hepatotoxic metabolite hydrazine, toxic-free radicals and mono-methylhydrazine. Degradation by acetylation occurs via N-acetyltransferase-2 gene (NAT2); a deficiency of the NAT enzyme can lead to accumulation of hepatotoxic metabolite. Ten percent of patients with anti-tubercular drug-induced hepatotoxicity show progression to acute liver failure; the rest are self-limited (Badrinath and John 2018).

If the serum bilirubin rises to $\geq 3 \mathrm{mg} / \mathrm{dL}$ or serum transaminases exceed more than five times the upper limit of normal (or exceed three times the upper limit of normal in a symptomatic patient), all drugs should be stopped (Nahid et al. 2016). The decision on what regimen to use on restarting should be individualized. The regimen, even if retailed, might then still include one or more potentially hepatotoxic drugs, and these should be restarted one at a time, only when liver function tests return to their baseline (e.g. the transaminases fall to less than twice normal). In general, a cholestatic type of derangement would prompt addition of INH first; with a non-cholestatic picture, rifampicin could first be added (Sterling). Needless to say, careful monitoring with frequent testing of serum liver function is required. Most physicians would omit pyrazinamide when restarting ATT except in the mildest of cases or with other compelling reasons (Sterling).

Patients receiving ethambutol (EMB) should be questioned regarding their vision at each monthly visit. Monthly visual acuity and colour vision discrimination testing is recommended in those patients in whom EMB doses of greater than $15-20 \mathrm{mg} / \mathrm{kg}$ are being used, those who have been taking ethambutol for longer than 2 months and those with renal insufficiency in whom the levels of drug may be expected to rise (Blumberg et al. 2003). 
For patients who require a regimen with no hepatotoxic agents, potential agents include ethambutol, levofloxacin or moxifloxacin, an injectable agent and other second-line oral drugs. The optimal choice of agents and duration of treatment (at least 18-24 months) is uncertain. (See "Antituberculous drugs: An overview", section on "Second-line agents".)

\subsection{The Prevention of TB}

In the end, efforts to finally eradicate TB will need to hinge upon preventative aspects as much as upon its treatment. These strategies would include currently established practices, as well as novel strategies. The former include the following.

\subsubsection{Vaccines}

Tuberculosis is now the primary cause of death from infectious diseases exceeding HIV, AIDS and malaria. The WHO estimates 10.4 million new cases and 1.7 million deaths every year (WHO Global TB report 2017). Of these, 0.4 million are HIV patients who die mostly in LMIC (low- and middle-income countries) (WHO Global TB report 2017; www.who.int). Within the next 16 years, the goal is to reduce TB incidence by $90 \%$ but the progress has been painfully slow. The most effective way to reduce the burden of TB in the community, to date, has been to identify patients affected with TB as early as possible and to treat them effectively with antitubercular therapy.

The role of vaccines in this regard, though potentially vital, has been disappointing. Of all vaccine tested to date, the bacillus Calmette-Guerin (BCG) - a live attenuated vaccine that was made in 1919 after an incredible 11 years and 231 sub-cultures (Hasan 2014) - is still the most effective vaccine we have today. Yet its effect has been inconsistent, ranging from $80 \%$ to zero protection; several factors including geographical differences appear to play a role (British adolescents had better responses than South Indian participants perhaps due to background exposure to MTB or atypical mycobacteria). The efficacy of BCG has been most manifested in its protection of infants and young children from the dangerous forms of TB (such as disseminated "miliary" TB and TB meningitis). Also, its effects appear to wane with time (Hasan 2014).

The BCG is not a single vaccine. Several strains-all derived from the original 1921 BGC strain - are in use, which also partly explains its variable efficacy.

In 1998, the Sanger Centre in Cambridge, Britain and Paris's Pasteur Institute in France cracked the genetic code for the old $\mathrm{H} 37 \mathrm{Rv}$ strain of tubercle bacillus, and then, the genome of highly virulent CDC1551 (the "Oshkosh" strain) was mapped at the TIGR (Fine 1989). These developments have led to the possibility of exciting new candidate vaccines, several of which are in fact in the pipeline. 


\subsubsection{Treatment of Latent TB Infection (LTBI)}

It has been estimated that one-third of the world has been infected with TB bacteria. A relatively small number of immunocompetent individuals affected with LTBI will ever progress to active disease. Reactivation of TB occurs when the immune system is compromised by external factors such as steroids or other immunosuppressants or by immune deficiency syndromes, which enables the latent (dormant) bacteria to "awaken" causing active disease. There is unfortunately no test that can currently predict which of these individuals will progress to active disease immunocompromised individuals have a high possibility of doing so.

Given that perspective, treatment for latent TB infection is most relevant for children under 5 years, the elderly and individuals with HIV infection. To eliminate TB from the planet, a multipronged strategy incorporating early and effective treatment, vaccination and elimination of dormant reservoir of latent TB will be essential.

LTBI treatment with INH ("chemoprophylaxis") is still the mainstay for treating latent TB infection but given that treatment extends to 6 months, and that there is one death from hepatotoxicity for every 25,000-40,000 cases with such treatment, alternate strategies including rifamycin-based regimens are being explored (Rangaka et al. 2015).

\section{References}

Acar S, Keskin-Arslan E, Erol-Coskun H, Kaya-Temiz T, Kaplan YC (2019) Pregnancy outcomes following quinolone and fluoroquinolone exposure during pregnancy: a systematic review and meta-analysis. Reprod Toxicol 85:65-74. https://doi.org/10.1016/j.reprotox.2019.02.002

Badrinath B, John S. (2018) Isoniazid toxicity. StatPearls Publishing

Benator D, Bhattacharya M, Bozeman L, Burman W, Cantazaro A, Chaisson R, Gordin F, Horsburgh CR, Horton J, Khan A, Lahart C, Metchock B, Pachucki C, Stanton L, Vernon A, Villarino ME, Wang YC, Weiner M, Weis S (2002) Rifapentine and isoniazid once a week versus rifampicin and isoniazid twice a week for treatment of drug-susceptible pulmonary tuberculosis in HIV-negative patients: a randomised clinical trial. Lancet 360(9332):528-534

Bhalla M, Sidiq Z, Sharma P, Singhal R, Myneedu V, Sarin R (2013) Performance of light-emitting diode fluorescence microscope for diagnosis of tuberculosis. Int J Mycobacteriol 2(3):174-178. https://doi.org/10.1016/j.ijmyco.2013.05.001

Blumberg HM, Burman WJ, Chaisson RE, Daley CL, Etkind SC, Friedman LN, Fujiwara P, Grzemska M, Hopewell PC, Iseman MD, Jasmer RM, Koppaka V, Menzies RI, O’Brien RJ, Reves RR, Reichman LB, Simone PM, Starke JR, Vernon AA (2003) American Thoracic Society/Centers for Disease Control and Prevention/Infectious Diseases Society of America: treatment of tuberculosis. Am J Respir Crit Care Med 167(4):603-662. https://doi.org/10.1164/ rccm.167.4.603

Boyles TH, Hughes J, Cox V, Burton R, Meintjes G, Mendelson M (2014) False-positive Xpert (R) MTB/RIF assays in previously treated patients: need for caution in interpreting results. Int J Tuberc Lung Dis 18(7):876-878. https://doi.org/10.5588/ijtld.13.0853

Chaudhuri A (2017) Recent changes in technical and operational guidelines for tuberculosis control programme in India - 2016: a paradigm shift in tuberculosis control. J Assoc Chest Phys 5 (1):1-9. https://doi.org/10.4103/2320-8775.196644 
Cheng VC, Yew WW, Yuen KY (2005) Molecular diagnostics in tuberculosis. Eur J Clin Microbiol Infect Dis 24(11):711-720. https://doi.org/10.1007/s10096-005-0039-1

Colangeli R, Jedrey H, Kim S, Connell R, Ma S, Chippada Venkata UD, Chakravorty S, Gupta A, Sizemore EE, Diem L, Sherman DR, Okwera A, Dietze R, Boom WH, Johnson JL, Mac Kenzie WR, Alland D (2018) Bacterial factors that predict relapse after tuberculosis therapy. N Engl J Med 379(9):823-833. https://doi.org/10.1056/NEJMoa1715849

Fine PE (1989) The BCG story: lessons from the past and implications for the future. Rev Infect Dis 11(Suppl 2):S353-S359

Five-year follow-up of a controlled trial of five 6-month regimens of chemotherapy for pulmonary tuberculosis. Hong Kong Chest Service/British Medical Research Council (1987) Am Rev Respir Dis 136(6):1339-1342. https://doi.org/10.1164/ajrccm/136.6.1339

Friedrich SO, Rachow A, Saathoff E, Singh K, Mangu CD, Dawson R, Phillips PP, Venter A, Bateson A, Boehme CC, Heinrich N, Hunt RD, Boeree MJ, Zumla A, McHugh TD, Gillespie SH, Diacon AH, Hoelscher M (2013) Assessment of the sensitivity and specificity of Xpert MTB/RIF assay as an early sputum biomarker of response to tuberculosis treatment. Lancet Respir Med 1(6):462-470. https://doi.org/10.1016/s2213-2600(13)70119-x

Gao F, Ge X, Li M, Zheng X, Xiao L, Zhang G, Hua Y (2015) CT features of lung scar cancer. J Thorac Dis 7(3):273-280. https://doi.org/10.3978/j.issn.2072-1439.2015.02.07

Garcia-Basteiro AL, DiNardo A, Saavedra B, Silva DR, Palmero D, Gegia M, Migliori GB, Duarte R, Mambuque E, Centis R, Cuevas LE, Izco S, Theron G (2018) Point of care diagnostics for tuberculosis. Pulmonology 24(2):73-85. https://doi.org/10.1016/j.rppnen.2017. 12.002

Garcia-Zamalloa A, Taboada-Gomez J (2012) Diagnostic accuracy of adenosine deaminase and lymphocyte proportion in pleural fluid for tuberculous pleurisy in different prevalence scenarios. PLoS One 7(6):e38729. https://doi.org/10.1371/journal.pone.0038729

Global TB report 2017. vol 15/01/2019

Golub JE, Bur S, Cronin WA, Gange S, Baruch N, Comstock GW, Chaisson RE (2006) Delayed tuberculosis diagnosis and tuberculosis transmission. Int J Tuberc Lung Dis 10(1):24-30

Guidelines for treatment of drug-susceptible tuberculosis and patient care (2017) World Health Organization, Geneva

Hagan G, Nathani N (2013) Clinical review: tuberculosis on the intensive care unit. Crit Care 17 (5):240. https://doi.org/10.1186/cc12760

Hasan A. (2014) BCG-The waning of a vaccine. J Med Allied Sci

Heemskerk D, Caws M, Marais B, Farrar J (2015) Tuberculosis in adults and children. Springer, London

John MBS (2019) Isoniazid toxicity. StatPearls Publishing

Jolliffe DA, Ganmaa D, Wejse C, Raqib R, Haq MA, Salahuddin N, Daley PK, Ralph AP, Ziegler TR, Martineau AR (2019) Adjunctive vitamin D in tuberculosis treatment: meta-analysis of individual participant data. Eur Respir J:1802003. https://doi.org/10.1183/13993003.020032018

Kaufmann SH, Lange C, Rao M, Balaji KN, Lotze M, Schito M, Zumla AI, Maeurer M (2014) Progress in tuberculosis vaccine development and host-directed therapies - a state of the art review. Lancet Respir Med 2(4):301-320. https://doi.org/10.1016/s2213-2600(14)70033-5

Lambregts-van Weezenbeek CS, Veen J (1995) Control of drug-resistant tuberculosis. Tuber Lung Dis 76(5):455-459

Lange C, Chesov D, Heyckendorf J, Leung CC, Udwadia Z, Dheda K (2018) Drug-resistant tuberculosis: an update on disease burden, diagnosis and treatment. Respirology 23 (7):656-673. https://doi.org/10.1111/resp.13304

Lewinsohn DM, Leonard MK, LoBue PA, Cohn DL, Daley CL, Desmond E, Keane J, Lewinsohn DA, Loeffler AM, Mazurek GH, O’Brien RJ, Pai M, Richeldi L, Salfinger M, Shinnick TM, Sterling TR, Warshauer DM, Woods GL (2017) Official American Thoracic Society/Infectious Diseases Society of America/Centers for Disease Control and Prevention clinical practice guidelines: diagnosis of tuberculosis in adults and children. Clin Infect Dis 64(2):111-115. https://doi.org/10.1093/cid/ciw778 
Loto OM, Awowole I (2012) Tuberculosis in pregnancy: a review. J Pregnancy 2012:379271. https://doi.org/10.1155/2012/379271

Mayer KH, Dukes Hamilton C (2010) Synergistic pandemics: confronting the global HIV and tuberculosis epidemics. Clin Infect Dis 50(Suppl 3):S67-S70. https://doi.org/10.1086/651475

Mayosi BM, Ntsekhe M, Bosch J, Pandie S, Jung H, Gumedze F, Pogue J, Thabane L, Smieja M, Francis V, Joldersma L, Thomas KM, Thomas B, Awotedu AA, Magula NP, Naidoo DP, Damasceno A, Chitsa Banda A, Brown B, Manga P, Kirenga B, Mondo C, Mntla P, Tsitsi JM, Peters F, Essop MR, Russell JB, Hakim J, Matenga J, Barasa AF, Sani MU, Olunuga T, Ogah O, Ansa V, Aje A, Danbauchi S, Ojji D, Yusuf S (2014) Prednisolone and mycobacterium indicus pranii in tuberculous pericarditis. N Engl J Med 371(12):1121-1130. https://doi.org/10.1056/ NEJMoa1407380

Morgan MA, Horstmeier CD, DeYoung DR, Roberts GD (1983) Comparison of a radiometric method (BACTEC) and conventional culture media for recovery of mycobacteria from smearnegative specimens. J Clin Microbiol 18(2):384-388

Murray JF (2014) Tuberculosis and high altitude. Worth a try in extensively drug-resistant tuberculosis? Am J Respir Crit Care Med 189(4):390-393. https://doi.org/10.1164/rccm. 201311-2043OE

Nahid P, Dorman SE, Alipanah N, Barry PM, Brozek JL, Cattamanchi A, Chaisson LH, Chaisson RE, Daley CL, Grzemska M, Higashi JM, Ho CS, Hopewell PC, Keshavjee SA, Lienhardt C, Menzies R, Merrifield C, Narita M, O'Brien R, Peloquin CA, Raftery A, Saukkonen J, Schaaf HS, Sotgiu G, Starke JR, Migliori GB, Vernon A (2016) Official American Thoracic Society/ Centers for Disease Control and Prevention/Infectious Diseases Society of America clinical practice guidelines: treatment of drug-susceptible tuberculosis. Clin Infect Dis 63(7): e147-e195. https://doi.org/10.1093/cid/ciw376

Pai M, Nicol MP, Boehme CC (2016) Tuberculosis diagnostics: state of the art and future directions. Microbiol Spectr 4(5). https://doi.org/10.1128/microbiolspec.TBTB2-0019-2016

Patel K, Goldman JL (2016) Safety concerns surrounding quinolone use in children. J Clin Pharmacol 56(9):1060-1075. https://doi.org/10.1002/jcph.715

Prasad R, Gupta N, Banka A (2018) Multidrug-resistant tuberculosis/rifampicin-resistant tuberculosis: principles of management. Lung India 35(1):78-81. https://doi.org/10.4103/lungindia. lungindia_98_17

Prevention CfDCa (2014) Reported tuberculosis in the United States, 2013 (trans: Services UDoHaH). Atlanta, GA

Rangaka MX, Cavalcante SC, Marais BJ, Thim S, Martinson NA, Swaminathan S, Chaisson RE (2015) Controlling the seedbeds of tuberculosis: diagnosis and treatment of tuberculosis infection. Lancet 386(10010):2344-2353. https://doi.org/10.1016/S0140-6736(15)00323-2

Raviglione MC (2017) Tuberculosis. In: Kasper DLaF, A.S (ed) Harrison's infectious diseases, 9th edn. McGraw-Hill Education, New York

Reported tuberculosis in the United States, 2013. (2014)

Rippon JW (1988) Medical mycology: the pathogenic fungi and the pathogenic actinomycetes, 3rd edn. Saunders, Philadelphia

Ruan LY, Fan JT, Hong W, Zhao H, Li MH, Jiang L, Fu YH, Xing YX, Chen C, Wang JS (2018) Isoniazid-induced hepatotoxicity and neurotoxicity in rats investigated by (1)H NMR based metabolomics approach. Toxicol Lett 295:256-269. https://doi.org/10.1016/j.toxlet.2018.05. 032

Sadanand S (2011) Harrison's infectious diseases. Yale J Biol Med 84(3):327-328

Sharma S, Mohan A, Sharma A (2016) Miliary tuberculosis: a new look at an old foe. J Clin Tuberc Other Mycobact Dis 3. https://doi.org/10.1016/j.jctube.2016.03.003

Shinnick TM, Good RC (1995) Diagnostic mycobacteriology laboratory practices. Clin Infect Dis 21(2):291-299

Skrahin A, Ahmed RK, Ferrara G, Rane L, Poiret T, Isaikina Y, Skrahina A, Zumla A, Maeurer MJ (2014) Autologous mesenchymal stromal cell infusion as adjunct treatment in patients with multidrug and extensively drug-resistant tuberculosis: an open-label phase 1 safety trial. Lancet Respir Med 2(2):108-122. https://doi.org/10.1016/s2213-2600(13)70234-0 
Steingart KR, Schiller I, Horne DJ, Pai M, Boehme CC, Dendukuri N (2014) Xpert(R) MTB/RIF assay for pulmonary tuberculosis and rifampicin resistance in adults. Cochrane Database Syst Rev (1):Cd009593. https://doi.org/10.1002/14651858.CD009593.pub3

Sterling TR. Treatment of drug-susceptible pulmonary tuberculosis in HIV-uninfected adults. https://www.uptodate.com/contents/treatment-of-drug-susceptible-pulmonary-tuberculosis-inhiv-uninfected-adults. Accessed 21 Feb 2019

Targeted tuberculin testing and treatment of latent tuberculosis infection. This official statement of the American Thoracic Society was adopted by the ATS Board of Directors, July 1999. This is a Joint Statement of the American Thoracic Society (ATS) and the Centers for Disease Control and Prevention (CDC). This statement was endorsed by the Council of the Infectious Diseases Society of America. (IDSA), September 1999, and the sections of this statement (2000) Am J Respir Crit Care Med 161(4 Pt 2):S221-S247. https://doi.org/10.1164/ajrccm.161.supple ment_3.ats600

Tatar D, Senol G, Kirakli C, Edipoglu O, Cimen P (2018) Contributing factors to mortality rates of pulmonary tuberculosis in intensive care units. J Chin Med Assoc 81(7):605-610. https://doi. org/10.1016/j.jcma.2018.02.003

van den Heuvel MM, van Rensburg JJ (2006) Images in clinical medicine. Rasmussen's aneurysm. N Engl J Med 355(16):e17. https://doi.org/10.1056/NEJMicm050783

WHO Global TB report 2017. www.who.int.

WHO treatment guidance for drug resistant tuberculosis (2016)

WHO treatment guidelines for multidrug- and rifampicin-resistant tuberculosis (2018) https://www. who.int/tb/publications/2018/WHO.2018.MDR-TB.Rx.Guidelines.prefinal.text.pdf

Ziganshina LE, Squire SB (2008) Fluoroquinolones for treating tuberculosis. Cochrane Database Syst Rev (1):Cd004795. https://doi.org/10.1002/14651858.CD004795.pub3 